\title{
In Situ Reduced MXene/AuNPs Composite Toward Enhanced Charging/discharging and Specific Capacitance
}

\section{Zixiang Zheng}

University of Science and Technology Beijing

\section{Wei Wu}

University of Science and Technology Beijing

Tao Yang

University of Science and Technology Beijing

Enhui Wang

University of Science and Technology Beijing

Zhentao Du

Guangxi University

Xinmei Hou ( $\nabla$ houxinmeiustb@ustb.edu.cn ) University of Science and Technology Beijing

Tongxiang Liang

JiangXi University of Science and Technology

Hailong Wang

Zhengzhou University

\section{Research Article}

Keywords: Supercapacitors, MXene, AuNPs, self-reduction, composite

Posted Date: February 10th, 2021

DOl: https://doi.org/10.21203/rs.3.rs-210990/v1

License: (1) (1) This work is licensed under a Creative Commons Attribution 4.0 International License. Read Full License 


\section{Abstract}

In this work, gold nanoparticles (AuNPs) decorated $\mathrm{Ti}_{3} \mathrm{C}_{2} \mathrm{~T}_{\mathrm{x}}$ nanosheets (MXene/AuNPs composite) are fabricated through a self-reduction reaction of $\mathrm{Ti}_{3} \mathrm{C}_{2} \mathrm{~T}_{\mathrm{x}}$ nanosheets with $\mathrm{HAuCl}_{4}$ aqueous solution. The obtained composite is characterized as AuNPs with the diameter of about $20 \mathrm{~nm}$ uniformly disperse on $\mathrm{Ti}_{3} \mathrm{C}_{2} \mathrm{~T}_{\mathrm{x}}$ nanosheets without aggregation. The composite (MXene decorated on $4.8 \mathrm{wt} . \%$ AuNPs) is further employed to construct supercapacitor for the first time with a higher specific capacitance of $278 \mathrm{~F} \mathrm{~g}^{-1}$ at 5 $\mathrm{mV} \mathrm{s}^{-1}$ than that of pure $\mathrm{Ti}_{3} \mathrm{C}_{2} \mathrm{~T}_{\mathrm{x}}$ and $95 \%$ of cyclic stability after 10000 cycles. Furthermore, MXene/AuNPs composite symmetric supercapacitor with filter paper as separator and $\mathrm{H}_{2} \mathrm{SO}_{4}$ as electrolyte, respectively, is assembled. The supercapacitor exhibits a high volumetric energy density of 8.82 Wh L $\mathrm{L}^{-1}$ at a power density of $264.6 \mathrm{~W} \mathrm{~L}^{-1}$ and ultrafast-charging/discharging performance. It exhibits as a promising candidate applied in integrated and flexible supercapacitors.

\section{Introduction}

On account of excellent cycle stability, high rate of charge/discharge and high-power density, supercapacitors have caught great attention during these years. [1-3]Now one of the key challenges in making supercapacitors is in improving the energy density. [4] Researchers concentrate on exploring and developing the electrode materials with excellent performance, which are key ingredients for high performance supercapacitors. [5-7] Two-dimensional (2D) materials are among the most promising electrode materials for supercapacitors. Due to their high surface-area-to-volume ratios, 2D materials offer an abundance of active surface area for charge storage through electric double layer capacitance (EDLC) or fast surface redox reactions (pseudocapacitance). [8] During the last decade, due to relatively better chemical stability, higher specific surface area and active surface sites, excellent hydrophilicity and higher electrical conductivity, $[9,10]$ transition metal carbides and/or nitrides (MXene) as a novel family of 2D materials have been applied in different areas including energy storage, [11-13] water desalination, [14] catalysis, [15] electromagnetic interference shielding, [16] and transparent conductive films. [17] The general formula of MXenes is $M_{n+1} X_{n} T_{x}(n=1-3)$, where $M$ represents a transition metal (such as Sc, Ti, $\mathrm{Zr}$ ), $\mathrm{X}$ is carbon and/or nitrogen and $\mathrm{T}$ stands for the surface terminations (for example, hydroxyl, oxygen, or fluorine). [10] The earliest exploring and the most widely applied MXene is $\mathrm{Ti}_{3} \mathrm{C}_{2} \mathrm{~T}_{\mathrm{x}}$ which shows exceptional performances as a potential electrode material for supercapacitors. [18]

However, due to the presence of van der Waals force, almost all of 2D materials, including MXene, have the inevitable problems of aggregation and self-restacking. [19] This problem prevents electrolyte penetration into layers, limits the ion transport and reduces the active site in supercapacitors. Therefore the restacking has become a huge obstacle to ameliorate the performance of MXene. [20-23] In order to overcome this shortcoming, various interlayer spacers are introduced to prevent the stacking between the MXene nanosheets which can accelerate electrolyte penetration, the ion transport, and increase the active site. $[24,25]$ These include carbon nanomaterials such as carbon nanotubes (CNTs) [26] and graphene, $[27,28]$ conductive polymers such as polypyrrole (PPy), [29] poly(3,4-ethylenedioxythiophene) (PEDOT) 
[30] and polyaniline (PANI), [31] and metal nanoparticles such as silver nanoparticles (AgNPs) [32] and gold nanoparticles (AuNPs). [24,33] In particular, since AuNPs is one of the highest conductivity metals with large specific surface area and high stability at the nanoscale level, it can be available for high performance energy storage devices. [34] To date, there are no reports about $\mathrm{Ti}_{3} \mathrm{C}_{2} \mathrm{~T}_{\mathrm{x}}$ nanosheets modified by AuNPs to improve the electrochemical properties.

In this work, AuNPs decorated $\mathrm{Ti}_{3} \mathrm{C}_{2} \mathrm{~T}_{\mathrm{x}}$ nanosheets were fabricated through a self-reduction reaction of $\mathrm{Ti}_{3} \mathrm{C}_{2} \mathrm{~T}_{\mathrm{x}}$ with $\mathrm{HAuCl}_{4}$ aqueous solution. By vacuum filtration of the mixture solution, freestanding composite films were fabricated. Then MXene/AuNPs composite was used as electrode material of supercapacitors for the first time. MXene/AuNPs electrodes showed significantly enhanced electrochemical property compares to the pure $\mathrm{Ti}_{3} \mathrm{C}_{2} \mathrm{~T}_{\mathrm{x}}$ electrodes. The integrated device can power a red light emitting diode (LED), demonstrating its energy storage capacity.

\section{Experimental}

\subsection{Materials}

High-purity $\mathrm{Ti}_{3} \mathrm{AlC}_{2}$ MAX phase powders (99 wt.\%) were supplied by Kaikai Materials Co. Ltd., China. $\mathrm{HAuCl}_{4}$ was purchased from Sinopharm Chemical Reagent Co., Ltd., China. Xinya Equipment Co., LTD, China. supplied cellulose membrane with $0.44 \mu \mathrm{m}$ pore size and $\varnothing 50 \mathrm{~mm}$ in diameter. The coin cell (CR2032-CASE-304Pt, coating Pt of the thickness of 300-500 A) was supplied by Hefei Kejing Materials Technology Co., Ltd., China.

\subsection{Preparation of MXene/AuNPs composite}

In view of the preparation of $\mathrm{Ti}_{3} \mathrm{C}_{2} \mathrm{~T}_{x}$, minimally intensive layer delamination (MILD) method was used. [35] Briefly, $12 \mathrm{M} \mathrm{HCl}$ of $40 \mathrm{~mL}$ solution and LiF of $2 \mathrm{~g}$ mixed with stirring of $30 \mathrm{~min}$. After the powder was completely dissolved, $\mathrm{Ti}_{3} \mathrm{AlC}_{2}$ powders of $2 \mathrm{~g}$ mixed slowly with the $\mathrm{LiF}-\mathrm{HCl}$ solution. The as-prepared solution was stirred with $500 \mathrm{rpm}$ for $24 \mathrm{~h}$ at $35^{\circ} \mathrm{C}$. The suspension was completely transferred to a centrifuge tube. Then the etched powder was washed using deionized water to ensure the $\mathrm{pH}$ value of the solution higher than 6 . Each wash process included $2500 \mathrm{rpm}$ for $3 \mathrm{~min}$ centrifugation and 2-4 min hand shaking. The as-prepared multilayer $\mathrm{Ti}_{3} \mathrm{C}_{2} \mathrm{~T}_{\mathrm{x}}$ powder was dispersed in $100 \mathrm{~mL}$ deionized water by sonicating $1 \mathrm{~h}$ and centrifuging at $3500 \mathrm{rpm}$ to obtain the $\mathrm{Ti}_{3} \mathrm{C}_{2} \mathrm{~T}_{\mathrm{x}}$ colloidal solution. Finally $\mathrm{Ti}_{3} \mathrm{C}_{2} \mathrm{~T}_{\mathrm{x}}$ film was obtained by vacuum filtered on a cellulose membrane filter.

Based on this, the $\mathrm{Ti}_{3} \mathrm{C}_{2} \mathrm{~T}_{\mathrm{x}}$ film was dispersed in deionized water to obtain a uniform suspension ( $1 \mathrm{mg}$ $\mathrm{mL}^{-1}$ ). Then, $\mathrm{HAuCl}_{4}(1 \mathrm{wt}$.\%) solution with different volume of 125,250 and $500 \mu \mathrm{L}$ was slowly added to $30 \mathrm{~mL} \mathrm{Ti}{ }_{3} \mathrm{C}_{2} \mathrm{~T}_{\mathrm{x}}$ aqueous solution. The corresponding mixture was named as MXene/AuNPs-1 (2.4 wt.\% AuNPs), MXene/AuNPs-2 (4.8 wt.\% AuNPs) and MXene/AuNPs-3 (9.6 wt.\% AuNPs). After stirring for 20 min, the obtained composite suspension was filtered on a cellulose membrane filter by vacuum filtration, 
dried at room temperature for $24 \mathrm{~h}$. Then, flexible and freestanding MXene/AuNPs composite film (about $30 \mathrm{mg}$ ) was obtained.

\subsection{Characterization}

$\mathrm{Ti}_{3} \mathrm{C}_{2} \mathrm{~T}_{\mathrm{x}}$ and $\mathrm{MXene/AuNPs}$ samples were characterized by a scanning electron microscopy (FEl, Nova 230, SEM) with energy dispersive spectrometer (EDS), X-ray powder diffraction (TTRIII, Rigaku, XRD), transmission electron microscopy (FEI, Tecnai G2 F30, TEM) and X-ray photoelectron spectroscopy (VG Multilab 2009, Al Ka, XPS). The specific surface area was determined from the nitrogen adsorptiondesorption isotherm measured at 77K using Brunauer-Emmett-Teller model (Micromeritics ASAP 2010, $B E T$ ). The conductivity of samples were characterized by precision source/measurement unit (Keysight B2911).

\subsection{Electrochemical measurements}

CHI 660E electrochemical workstation was used in all electrochemical measurements. In a three-electrode system, electrochemical properties of $\mathrm{Ti}_{3} \mathrm{C}_{2} \mathrm{~T}_{\mathrm{x}}$ and MXene/AuNPs electrode were studied by cyclic voltammetry (CV), galvanostatic charging/discharging (GCD) and electrochemical impedance spectroscopy (EIS) in $1 \mathrm{M} \mathrm{H}_{2} \mathrm{SO}_{4}$ electrolyte. $\mathrm{Ag} / \mathrm{AgCl}$ was served as reference electrodes, $\mathrm{Pt}$ sheet was used as the counter electrodes and $\mathrm{Ti}_{3} \mathrm{C}_{2} \mathrm{~T}_{\mathrm{x}}$ and MXene/AuNPs were served as the working electrode. $\mathrm{A}$ symmetric supercapacitor was sandwiched in a coin cell with MXene/AuNPs composite film ( $\$ 16 \mathrm{~mm}$ in diameter) as electrodes, filter paper ( $\$ 20 \mathrm{~mm}$ in diameter) as separator and $1 \mathrm{M} \mathrm{H}_{2} \mathrm{SO}_{4}$ as electrolyte.

\section{Results And Discussion}

\subsection{Characterization and preparation mechanism}

Fabrication of MXene/AuNPs composite film is shown in Fig.1. By selective etching of $\mathrm{Al}$ layer of $\mathrm{Ti}_{3} \mathrm{AlC}_{2}$ powders, multilayer $\mathrm{Ti}_{3} \mathrm{C}_{2} \mathrm{~T}_{x}$ powders are obtained. Then, multilayer $\mathrm{Ti}_{3} \mathrm{C}_{2} \mathrm{~T}_{x}$ powders are sonicated into $\mathrm{Ti}_{3} \mathrm{C}_{2} \mathrm{~T}_{\mathrm{x}}$ nanosheets. There are functional groups on the surface of $\mathrm{Ti}_{3} \mathrm{C}_{2} \mathrm{~T}_{\mathrm{x}}$ nanosheets, such as $-\mathrm{F},-\mathrm{O}$ and $-\mathrm{OH}$. These functional groups make $\mathrm{Ti}_{3} \mathrm{C}_{2} \mathrm{~T}_{\mathrm{x}}$ nanosheets have a dispensability in aqueous solutions. Finally, adding the $\mathrm{HAuCl}_{4}$ solution into $\mathrm{Ti}_{3} \mathrm{C}_{2} \mathrm{~T}_{x}$ nanosheets dispersion, the composite material will be formed due to the reduction reaction between $\mathrm{AuCl}_{4}{ }^{-}$and the functional groups on the surface of $\mathrm{Ti}_{3} \mathrm{C}_{2} \mathrm{~T}_{\mathrm{x}}$ nanosheets. Additionally, this film obtained by vacuum filtration can be easily wrapped around a glass bar and retain its integrity, as showed in Fig.1, indicating good flexibility.

From Fig. 2, the high diffraction peak at $6.9^{\circ}$ for $\mathrm{Ti}_{3} \mathrm{C}_{2} \mathrm{~T}_{x}$ corresponds to the (002) facet, suggesting the existing of the $\mathrm{Ti}_{3} \mathrm{C}_{2} \mathrm{~T}_{x}$ phase. For the MXene/AuNPs composite film, the (002) peak positions of $\mathrm{Ti}_{3} \mathrm{C}_{2} \mathrm{~T}_{x}$ do not vary, implying that no Au intercalation occurs. [9] The four diffraction peaks, as shown in Fig. 2, at $38.1^{\circ}, 44.4^{\circ}, 64.5^{\circ}$ and $77.5^{\circ}$ correspond to (111), (200), (220) and (311) planes of AuNPs. As $\mathrm{HAuCl}_{4}$ 
content increasing, the four diffraction peaks become stronger and sharper, implying that the content of AuNPs decorated on $\mathrm{Ti}_{3} \mathrm{C}_{2} \mathrm{~T}_{x}$ is increasing.

In view of the morphology of the pure $\mathrm{Ti}_{3} \mathrm{C}_{2} \mathrm{~T}_{x}$ film (Fig. S1), the surface is crumpled (Fig. S1(a)). The $\mathrm{Ti}_{3} \mathrm{C}_{2} \mathrm{~T}_{\mathrm{x}}$ nanosheets have analogous wrinkles and high transparency, which are similar to graphene features (Fig. S1(b)). The HRTEM image shows that the fringes spacing of $0.253 \mathrm{~nm}$ corresponds to the (002) lattice planes of $\mathrm{Ti}_{3} \mathrm{C}_{2} \mathrm{~T}_{x}$ (Fig. S1(c)). The SAED pattern (Fig. S1(d)) shows characteristic diffraction rings corresponding to the (002) planes of $\mathrm{Ti}_{3} \mathrm{C}_{2} \mathrm{~T}_{\mathrm{x}}$, clearly revealing the polycrystal of $\mathrm{Ti}_{3} \mathrm{C}_{2} \mathrm{~T}_{\mathrm{x}}$. As shown in Figs. 3(a) and (b), MXene/AuNPs composite film exhibit similar morphology of pure $\mathrm{Ti}_{3} \mathrm{C}_{2} \mathrm{~T}_{x}$ film, but the surface is relatively rougher. Figs. $3(\mathrm{~b})$ and (d) reveal a uniform distribution of AuNPs on $\mathrm{Ti}_{3} \mathrm{C}_{2} \mathrm{~T}_{\mathrm{x}}$ nanosheets with the average particle size about $20 \mathrm{~nm}$ (Fig. 3(e)). The film exhibits crumpled morphology and stacked by layers (Fig. 3(c)). As shown in Fig. 3(e), the HRTEM image shows that the fringes spacing of $0.235 \mathrm{~nm}$ and $0.203 \mathrm{~nm}$ corresponds to the (111) and (200) lattice planes of Au. The SAED pattern (Fig. 3(f)) shows characteristic diffraction rings corresponding to the (200) and (220) planes of Au. Fig. S2 and Table S1 are the EDS of MXene/AuNPs composite, indicating that AuNPs are decorated on the surface of $\mathrm{Ti}_{3} \mathrm{C}_{2} \mathrm{~T}_{\mathrm{x}}$ nanosheets after $\mathrm{HAuCl}_{4}$ treatment in the absence of reducing agents and under the ambient condition.

The full XPS spectrum of $\mathrm{Ti}_{3} \mathrm{C}_{2} \mathrm{~T}_{x}$ and MXene/AuNPs is showed in Fig. 4(a). The presence of MXene together with $-\mathrm{F},-\mathrm{Cl},-\mathrm{OH}$ and $-\mathrm{O}$ groups can be proved by observing the common peaks of $\mathrm{Ti} 2 \mathrm{p}, \mathrm{C} 1 \mathrm{~s}, \mathrm{~F}$ 1s, $\mathrm{Cl} 2 \mathrm{p}$ and 0 1s from 0 to $800 \mathrm{eV}$. The $\mathrm{C} 1 \mathrm{~s}$ spectrums of $\mathrm{Ti}_{3} \mathrm{C}_{2} \mathrm{~T}_{\mathrm{x}}$ and MXene/AuNPs both have four characteristic peaks locating at 288.9, 286.4, 284.8, and $282.1 \mathrm{eV}$, as shown in Fig. 4(b) and (f), which corresponds to the groups of $\mathrm{O}-\mathrm{C}=\mathrm{O}, \mathrm{C}-\mathrm{OH}, \mathrm{C}-\mathrm{C}$, and $\mathrm{C}-\mathrm{Ti}-\mathrm{O}$. [36, 37] As shown in the Fig. 4(c) and (g), the Ti $2 p$ spectrums of $\mathrm{Ti}_{3} \mathrm{C}_{2} \mathrm{~T}_{\mathrm{x}}$ and MXene/AuNPs are both indexed with three characteristic peaks locating at 454.5, 455.9, and 457.4, corresponding to tetravalent $\mathrm{Ti}-\mathrm{C}, \mathrm{Ti}-\mathrm{X}\left(\mathrm{TiC}_{\mathrm{x}}, \mathrm{x}<1\right)$, and $\mathrm{Ti}_{\mathrm{x}} \mathrm{O}_{y}$, but there is a characteristic peak locating at $455.8 \mathrm{eV}$ in the Ti $2 p$ spectrums of MXene/AuNPs corresponding to $\mathrm{TiO}_{2}$, indicating the slight oxidation of $\mathrm{Ti}_{3} \mathrm{C}_{2} \mathrm{~T}_{\mathrm{x}}$ after mixing with $\mathrm{HAuCl}_{4}$. [38-40] The $01 \mathrm{~s}$ spectrums of $\mathrm{Ti}_{3} \mathrm{C}_{2} \mathrm{~T}_{\mathrm{x}}$ and MXene/AuNPs both have four characteristic peaks locating at $529.8 \mathrm{eV}, 531.2 \mathrm{eV}, 532.0 \mathrm{eV}$, and $533.8 \mathrm{eV}$, corresponding to the groups of absord $\mathrm{O}, \mathrm{C}-\mathrm{Ti}-\mathrm{O}_{\mathrm{x}}, \mathrm{C}-\mathrm{Ti}-\mathrm{OH}$, and $\mathrm{C}-\mathrm{OH}$, as shown in Fig. $4(\mathrm{~d})$ and (h). The content of $\mathrm{O}$ of MXene/AuNPs reduce by $27 \%$ than that of $\mathrm{Ti}_{3} \mathrm{C}_{2} \mathrm{~T}_{\mathrm{x}}$, as determined by XPS. As shown in Fig. 4(e), Au $4 \mathrm{f}$ spectrum of MXene/AuNPs shows two peaks characteristic peaks locating at $84.0 \mathrm{eV}$ and $87.7 \mathrm{eV}$ where the binding energy difference is $3.7 \mathrm{eV}$, manifest the presence of $\mathrm{Au}^{0}$.

From above results, the AuNPs are assembled and decorated on the surfaces of $\mathrm{Ti}_{3} \mathrm{C}_{2} \mathrm{~T}_{\mathrm{x}}$ nanosheets evenly. It should be pointed out that no additional reducing agent was added in this work. Cheng et al. have demonstrated that MXenes with $-\mathrm{OH}$ terminations can reduce noble metal ions into zero-valent metals. [41] Since the surface of $\mathrm{Ti}_{3} \mathrm{C}_{2} \mathrm{~T}_{\mathrm{x}}$ nanosheets are covered by $-\mathrm{F},-\mathrm{O}$ and $-\mathrm{OH}, \mathrm{AuCl}_{4}{ }^{-}$can be directly reduced by $-\mathrm{OH}$ and formed AuNPs [42]: 


\section{$\mathrm{AuCl}_{4}^{-}+3 e \rightarrow \mathrm{Au}^{0} \downarrow+4 \mathrm{Cl}^{-}$}

which is consistent with reduction in 0 content calculated above.

The AuNPs and $\mathrm{Ti}_{3} \mathrm{C}_{2} \mathrm{~T}_{\mathrm{x}}$ nanosheets are combined into a structure of conducting network, which depicts the pronounced contributions of AuNPs to the enhancement of conductivity. This structure contributes to accelerate electrolyte penetration, the ion transport, and increase the active site in electrochemical reaction.

\subsection{Electrochemical property of MXene/AuNPs electrode}

Fig. 5(a) shows the CV curves of $\mathrm{Ti}_{3} \mathrm{C}_{2} \mathrm{~T}_{\mathrm{x}}$ and MXene/AuNPs electrodes at $5 \mathrm{mV} \mathrm{s}^{-1}$ in $1 \mathrm{M} \mathrm{H}_{2} \mathrm{SO}_{4}$ solution. Due to the contribution of pseudocapacitance derived from the varied valence of transition metal Ti atoms, $\mathrm{CV}$ curves of $\mathrm{Ti}_{3} \mathrm{C}_{2} \mathrm{~T}_{\mathrm{x}}$ and MXene/AuNPs film exhibit deformed rectangle shape. According to the CV curves of $\mathrm{Ti}_{3} \mathrm{C}_{2} \mathrm{~T}_{x}$, MXene/AuNPs-1, MXene/AuNPs-2, and MXene/AuNPs-3 electrodes, the specific capacitance are calculated as $228 \mathrm{~F} \mathrm{~g}^{-1}, 234 \mathrm{~F} \mathrm{~g} \mathrm{~g}^{-1}, 278 \mathrm{~F} \mathrm{~g}^{-1}$, and $250 \mathrm{~F} \mathrm{~g}^{-1}$, respectively. MXene/AuNP-2 composite electrode shows the largest CV area, which is about 1.2 times larger than that of $\mathrm{Ti}_{3} \mathrm{C}_{2} \mathrm{~T}_{\mathrm{x}}$ electrode, indicating it possesses better electrochemical capacitive performance by wedging AuNPs. Fig.5(b) presents CV curves of MXene/AuNPs-2 vary from $5 \mathrm{mV} \mathrm{s}^{-1}$ to $100 \mathrm{mV} \mathrm{s}^{-1}$. The shape deformation of $\mathrm{CV}$ curves becomes heavier with the scan rate increasing. This phenomenon is possibly caused by slow ion response at high rates. GCD measurement was performed to investigate electrochemical performance of MXene/AuNPs-2 at current density ranging from $1 \mathrm{~A} \mathrm{~g}^{-1}$ to 10 $\mathrm{A} \mathrm{g}^{-1}$ as shown in Fig. 5(c). GCD curves of MXene/AuNPs are almost symmetric and linear triangles, indicating that MXene/AuNPs has reversible charge/discharge process and good capacitance behavior. Inset of Fig. 5(c) is the coulombic efficiency (CE) calculated from different current density. The calculated results of $1 \mathrm{~A} \mathrm{~g}^{-1}, 2 \mathrm{~A} \mathrm{~g}^{-1}, 5 \mathrm{~A} \mathrm{~g}^{-1}$, and $1 \mathrm{~A} \mathrm{~g}^{-1}$ are $72.8 \%, 86.5 \%, 97.4 \%$ and $99.5 \%$, respectively, showing that MXene/AuNPs has a high coulombic efficiency. In view of the rate capability as shown in Fig. 5(d), the specific capacitance of $5 \mathrm{mV} / \mathrm{s}, 10 \mathrm{mV} / \mathrm{s}, 20 \mathrm{mV} / \mathrm{s}, 50 \mathrm{mV} / \mathrm{s}$, and $100 \mathrm{mV} / \mathrm{s}$ are $278 \mathrm{~F} \mathrm{~g}^{-1}, 251 \mathrm{~F} \mathrm{~g}^{-1}, 225 \mathrm{~F}$ $\mathrm{g}^{-1}, 198 \mathrm{~F} \mathrm{~g}^{-1}$, and $181 \mathrm{~F} \mathrm{~g}^{-1}$, indicating that MXene/AuNPs-2 retains about $65 \%$ of the initial capacitance. The good rate capability is attributed to the $2 \mathrm{D}$ structure and good conductivity of MXene/AuNPs, which allows rapid ion transport. It should be noted that the AuNPs have no capacitive contributions. Therefore, the specific capacitance decrease with the excessive addition of $\mathrm{HAuCl}_{4}$ solution. The Nyquist plots shown in Fig. 5(e) are composed of two regions with a semicircle at the high-frequency part and an inclined line at the low-frequency part. The intercept of the $X$-axis represents the equivalent series resistance, which is related to the resistance of the electrode. $[43,44]$ The equivalent series resistance of the MXene/AuNPs-2 (1.4 $\Omega$ ) shows the lowest resistance value compared to those of the $\mathrm{Ti}_{3} \mathrm{C}_{2} \mathrm{~T}_{\mathrm{x}}(2.5 \Omega)$, MXene/AuNPs-1 (1.5 $\Omega$ ) and MXene/AuNPs-3 (1.4 $\Omega$ ) electrodes. The semicircle represents the charge 
transfer resistance $\left(R_{c t}\right)$ at the electrode-electrolyte interface, which are $0.08 \Omega, 0.07 \Omega, 0.06 \Omega$ and $0.08 \Omega$

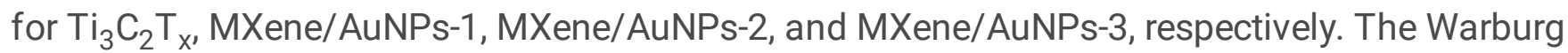
impedance stemming from the slope of the curve reflects the ion diffusion of the electrode, [45] which are 8.7 $\mathrm{S}^{1 / 2}, 8.5 \mathrm{~S}^{1 / 2}, 11.1 \mathrm{~S}^{1 / 2}$, and $8.3 \mathrm{~S}^{1 / 2}$ for $\mathrm{Ti}_{3} \mathrm{C}_{2} \mathrm{~T}_{x}$, MXene/AuNPs-1, MXene/AuNPs-2, and MXene/AuNPs-3, respectively. Among them, the MXene/AuNPs-2 electrode has the smallest $R_{c t}$ and the highest Warburg impedance, indicating excellent ion diffusion capabilities. The cyclic stability of MXene/AuNPs-2 electrodes is shown in Fig. $5(\mathrm{f})$. Notably, at $50 \mathrm{mV} \mathrm{s}^{-1}$, it exhibits excellent stability and the specific capacitance of MXene/AuNPs-2 still remains $95.0 \%$ after 10000 cycles.

The high stability and good electrochemical performance of MXene/AuNPs composite electrode could be mainly derived from three aspects. (1) As shown in Fig. 6(a), the AuNPs as the spacer prevents selfstacking between $\mathrm{Ti}_{3} \mathrm{C}_{2} \mathrm{~T}_{\mathrm{x}}$ nanosheets and lead to more space between the tightly stacked nanosheets, which significantly enlarge specific surface area of the composite material. [46] The BET results of $\mathrm{Ti}_{3} \mathrm{C}_{2} \mathrm{~T}_{\mathrm{x}}$ and MXene/AuNPs, as shown Fig. $6(\mathrm{~b})$, reveal that the specific surface area of MXene/AuNPs is about 1.8 times larger of $\mathrm{Ti}_{3} \mathrm{C}_{2} \mathrm{~T}_{\mathrm{x}}$. The larger specific surface area provides more active sites, improving the electrochemical performance. (2) The AuNPs as the spacer prevents self-stacking of $\mathrm{Ti}_{3} \mathrm{C}_{2} \mathrm{~T}_{\mathrm{x}}$ nanosheets, which is beneficial for electrolyte penetration and the transport of ions. [24] As shown in Fig. $5(\mathrm{e})$, the smaller $R_{\mathrm{S}}$ of MXene/AuNPs implies MXene/AuNPs have faster ion response and lower inherent resistance. (3) The conductivity of MXene/AuNPs composite is significantly improved due to AuNPs' excellent conductivity and the structure of conducting network between the AuNPs and $\mathrm{Ti}_{3} \mathrm{C}_{2} \mathrm{~T}_{\mathrm{x}}$ nanosheets. [46] As shown in Fig. S3the conductivity of MXene/AuNPs is 1.67 times higher than that of $\mathrm{Ti}_{3} \mathrm{C}_{2} \mathrm{~T}_{\mathrm{x}}$.

Compared with the performance of the various MXene-based supercapacitor reported in the literature (Table 1), the specific capacitance of MXene/AuNPs with an electrolyte of $1 \mathrm{M} \mathrm{H}_{2} \mathrm{SO}_{4}$ in this work is calculated to be $278 \mathrm{~F} \mathrm{~g}^{-1}\left(5 \mathrm{mV} \mathrm{s}^{-1}\right)$. This value is 1.2 times higher than that of MXene (i.e., $\left.238 \mathrm{~F} \mathrm{~g}^{-1}\right)$ and is better than that of $\mathrm{Ti}_{3} \mathrm{C}_{2} \mathrm{~T}_{X}-\mathrm{Cl}$, [47] $\mathrm{Ti}_{3} \mathrm{C}_{2} \mathrm{~T}_{X}$ clay, [48] and $\mathrm{Ti}_{3} \mathrm{C}_{2} \mathrm{~T}_{X}-\mathrm{N}_{2} \mathrm{H}_{4}$. [49]

Table 1. The key parameters of various MXene-based supercapacitor. 


\begin{tabular}{|c|c|c|c|}
\hline Material & Electrolyte & Specific capacitance & Ref. \\
\hline $\mathrm{Ti}_{3} \mathrm{C}_{2} \mathrm{~T}_{x}-\mathrm{Cl}$ & $1 \mathrm{M} \mathrm{H}_{2} \mathrm{SO}_{4}$ & $180 \mathrm{~F} \mathrm{~g}^{-1}\left(2 \mathrm{mV} \mathrm{s}^{-1}\right)$ & [47] \\
\hline $\mathrm{Ti}_{3} \mathrm{C}_{2} \mathrm{~T}_{x}$ clay & $1 \mathrm{M} \mathrm{H}_{2} \mathrm{SO}_{4}$ & $245 \mathrm{~F} \mathrm{~g}^{-1}\left(2 \mathrm{mV} \mathrm{s}^{-1}\right)$ & [48] \\
\hline $\mathrm{Ti}_{3} \mathrm{C}_{2} \mathrm{~T}_{x}-\mathrm{N}_{2} \mathrm{H}_{4}$ & $1 \mathrm{M} \mathrm{H}_{2} \mathrm{SO}_{4}$ & $250 \mathrm{~F} \mathrm{~g}^{-1}\left(5 \mathrm{mV} \mathrm{s}^{-1}\right)$ & [49] \\
\hline $\mathrm{Ti}_{3} \mathrm{C}_{2} \mathrm{~T}_{x}$ & $1 \mathrm{M} \mathrm{H}_{2} \mathrm{SO}_{4}$ & $238 \mathrm{~F} \mathrm{~g}^{-1}\left(5 \mathrm{mV} \mathrm{s}^{-1}\right)$ & [50] \\
\hline $\mathrm{N}-\mathrm{Ti}_{3} \mathrm{C}_{2} \mathrm{~T}_{x}$ & $1 \mathrm{M} \mathrm{H}_{2} \mathrm{SO}_{4}$ & $192 \mathrm{~F} \mathrm{~g}^{-1}\left(5 \mathrm{mV} \mathrm{s}^{-1}\right)$ & [51] \\
\hline $\mathrm{Ti}_{3} \mathrm{C}_{2} \mathrm{~T}_{x} / \mathrm{CNT}$ & $1 \mathrm{M} \mathrm{MgSO}_{4}$ & $117 \mathrm{Fg}^{-1}\left(2 \mathrm{mV} \mathrm{s}^{-1}\right)$ & [52] \\
\hline PANI- $\mathrm{Ti}_{3} \mathrm{C}_{2} \mathrm{~T}_{x}$ & $1 \mathrm{M} \mathrm{Na}_{2} \mathrm{SO}_{4}$ & $164 \mathrm{~F} \mathrm{~g}^{-1}\left(2 \mathrm{mV} \mathrm{s}^{-1}\right)$ & [53] \\
\hline d- $-\mathrm{Ti}_{3} \mathrm{C}_{2} \mathrm{~T}_{x}$ film & $1 \mathrm{M} \mathrm{KOH}$ & $140 \mathrm{~F} \mathrm{~g}^{-1}\left(5 \mathrm{mV} \mathrm{s}^{-1}\right)$ & [54] \\
\hline N-dope $\mathrm{Ti}_{3} \mathrm{C}_{2} \mathrm{~T}_{x}$ & $6 \mathrm{M} \mathrm{KOH}$ & $156 \mathrm{~F} \mathrm{~g}^{-1}\left(2 \mathrm{mV} \mathrm{s}^{-1}\right)$ & [55] \\
\hline $\mathrm{N}$-dope $\mathrm{Ti}_{3} \mathrm{C}_{2} \mathrm{~T}_{x}$ & $6 \mathrm{M} \mathrm{KOH}$ & $266 \mathrm{~F} \mathrm{~g}^{-1}\left(5 \mathrm{mV} \mathrm{s}^{-1}\right)$ & [56] \\
\hline $\mathrm{Ti}_{3} \mathrm{C}_{2} \mathrm{~T}_{x} / \mathrm{AuNPs}$ & $1 \mathrm{M} \mathrm{H}_{2} \mathrm{SO}_{4}$ & $278 \mathrm{~F} \mathrm{~g}^{-1}\left(5 \mathrm{mV} \mathrm{s}^{-1}\right)$ & This work \\
\hline
\end{tabular}

\subsection{Electrochemical performance of MXene/AuNPs symmetric supercapacitor}

To evaluate the performance of MXene/AuNPs-2 as supercapacitor, the cyclic voltammetry (CV), galvanostatic charging/discharging (GCD) and electrochemical impedance spectroscopy (EIS) were studied. In the working potential window of $0.0-0.6 \mathrm{~V}$ with the scan rates ranging from 5 to $100 \mathrm{mV} \mathrm{s}^{-1}$, as shown in Fig. 7(a), CV curves are almost rectangular, demonstrating its ideal characteristic of electrical double-layer capacitor and excellent rate capability. At current density ranging from $1 \mathrm{~A} \mathrm{~g}^{-1}$ to $10 \mathrm{~A} \mathrm{~g}^{-1}$, the GCD curves demonstrate a good capacitive performance due to its good linear potential-time profiles as well as nearly symmetrical with their discharging counterpart (as shown in Fig. 7(b)). There is no obvious semicircular in the high-frequency Nyquist diagram (Fig. 7(c)), indicating the low of $R_{c t}$ and the good electrical conductivity of the composite.The cyclic stability of MXene/AuNPs-2 electrodes is shown in Fig. 7(d). The specific capacitance of symmetric supercapacitor remains $95.0 \%$ after 10000 cycles at $50 \mathrm{mV}$ $\mathrm{s}^{-1}$, which exhibits excellent stability. As shown in Fig. S3 with the increase of the scanning rate, the gravimetric capacitance obviously decreases, which is due to slow ion transport rate. By calculation, the gravimetric capacitance is $213.8,196.1,186.4,160.9$ and $141.1 \mathrm{~F} \mathrm{~g}^{-1}$ from 100 to $5 \mathrm{mV} \mathrm{s}^{-1}$. Fig. 7(e) shows the comparation of the volumetric energy density and power density of MXene/AuNPs with other supercapacitors reported in the literature. Calculated from the data, the volumetric power density and energy density at $5,10,20,50,100 \mathrm{mV} \mathrm{s}^{-1}$ are calculated to be $264.6,485.3,922.7,1991.1,3492.2 \mathrm{~W} \mathrm{~L}^{-1}$ 
and 8.82, 8.09,7.69, 6.64, 5.82 $\mathrm{Wh} \mathrm{L}^{-1}$, respectively. Compared with MXene-based supercapacitor reported in the literature, for examples rGO//MXene (8.6 Wh L-1, $200 \mathrm{~W} \mathrm{~L}^{-1}$ ) [57], Ni-dMXNC//MXene(10.4 Wh L-1, $\left.220 \mathrm{~W} \mathrm{~L}^{-1}\right)$, [58] MP-MX ${ }_{1.5}\left(20.7 \mathrm{Wh} \mathrm{L}^{-1}, 184.8 \mathrm{~W} \mathrm{~L}^{-1}\right)$, [59] and $\mathrm{Ti}_{3} \mathrm{C}_{2} \mathrm{~T}_{\mathrm{x}}$ paper $\left(18.5 \mathrm{Wh} \mathrm{L}^{-1}, 240 \mathrm{~W} \mathrm{~L}^{-1}\right)$, [60] the energy density of MXene/AuNPs in this work are comparable to while the power density is higher than that of these MXene-based symmetric or asymmetric supercapacitor devices (Table S2). In addition, a red LED ( $1 \mathrm{~W}, 2.6 \mathrm{~V}-2.8 \mathrm{~V}, 350 \mathrm{~mA})$ is successfully powered by three prepared symmetric supercapacitors in series, as shown in the Fig. 7(f), convincingly demonstrating the energy storage capacity of MXene/AuNPs symmetric supercapacitor.

\section{Conclusion}

In summary, MXene/AuNPs composite is fabricated with AuNPs evenly distributed on the surface of $\mathrm{Ti}_{3} \mathrm{C}_{2} \mathrm{~T}_{x}$ nanosheets. The obtained AuNPs are directly reduced from $\mathrm{AuCl}_{4}{ }^{-}$by the groups of $-\mathrm{OH}$ on the surface of $\mathrm{Ti}_{3} \mathrm{C}_{2} \mathrm{~T}_{\mathrm{x}}$ nanosheets. The AuNPs and $\mathrm{Ti}_{3} \mathrm{C}_{2} \mathrm{~T}_{\mathrm{x}}$ nanosheets are combined into a structure of conducting network, which contributes to rapid electron transfer in electrochemical reactions. Composite electrodes (MXene decorated on 4.8 wt.\% AuNPs) show enhanced charge storage ability with a capacitance of $278 \mathrm{~F} \mathrm{~g}^{-1}$ at $5 \mathrm{mV} \mathrm{s}^{-1}$. The cyclic stability reaches $95.0 \%$ after 10000 cycles. Furthermore, a MXene/AuNPs symmetric supercapacitor with filter paper as separator and $\mathrm{H}_{2} \mathrm{SO}_{4}$ as electrolyte, exhibits a high volumetric energy density of $8.82 \mathrm{Wh} \mathrm{L}^{-1}$ at a power density of $264.6 \mathrm{~W} \mathrm{~L}^{-1}$. The integrated device can power a red LED demonstrating its energy storage capacity.

\section{Declarations}

\section{Acknowledgement}

Zixiang Zheng and Wei Wu contributed equally to this work. This work was supported by the National Science Fund for Distinguished Young Scholars (No. 52025041), the National Natural Science Foundation of China (No. 51974021, 51902020, 51904021), the Fundamental Research Funds for the Central Universities of NO. FRF-TP-18-045A1 and FRF-TP-19-004B2Z, the National Postdoctoral Program for Innovative Talents (BX20180034) and China Postdoctoral Science Foundation (Grant No. 2018M641192). This project is supported by open foundation of Guangxi Key Laboratory of Processing for Non-ferrous Metals and Featured Materials, Guangxi University (Grant No. 2021GXYSOF12).

\section{References}

[1] Pech D, Brunet M, Durou H, et al. Simon P, Ultrahigh-power micrometre-sized supercapacitors based on onion-like carbon. Nat. Nanotechnol 2010 5: 651-654.

[2] Yu Z, Tetard L, Zhai L, Thomas J, et al. Supercapacitor electrode materials: nanostructures from 0 to 3 dimensions. Energy Environ. Sci 2015 8: 702-730. 
[3] Wang B, Zhou A, Liu F, et al.. Carbon dioxide adsorption of two-dimensional carbide MXenes. J. Adv. Ceram. 2018, 7(3), 237-245.

[4] Yang C, Tang Y, Tian Y, et al. Flexible nitrogen-doped 2D titanium carbides (MXene) films constructed by an ex situ solvothermal method with extraordinary volumetric capacitance. Adv. Energy Mater. 2018, 8(31): 1802087.

[5] Yan P, Zhang R, Jia J, et al. Enhanced supercapacitive performance of delaminated two-dimensional titanium carbide/carbon nanotube composites in alkaline electrolyte, J. Power Sources 2015, 284: 38-43.

[6] Lin T, Chen IW, Liu F, et al. Nitrogen-doped mesoporous carbon of extraordinary capacitance for electrochemical energy storage, Science 2015, 350: 1508-1513.

[7] Gao Y, Wang L, Li Z, et al. Electrochemical performance of $\mathrm{Ti}_{3} \mathrm{C}_{2}$ supercapacitors in $\mathrm{KOH}$ electrolyte. J. Adv. Ceram. 2015, 4(2), 130-134.

[8] Tan C, Cao X, Wu XJ, et al. Recent advances in ultrathin two-dimensional nanomaterials, Chem. Rev. 2017, 117: 6225-6331.

[9] Naguib M, Mochalin VN, Barsoum MW, et al. 25th anniversary article: MXenes: a new family of twodimensional materials, Adv. Mater. 2014, 26: 992-1005.

[10] Anasor B i, Lukatskaya MR, Gogotsi Y, et al. 2D metal carbides and nitrides (MXenes) for energy storage, Nat. Rev. Mater. 2017, 2: 1-17.

[11] Liang X, Garsuch A, Nazar LF, et al. Sulfur cathodes based on conductive MXene nanosheets for high-performance lithium-sulfur batteries, Angew. Chem.-Int. Edit. 2015, 54: 3907-3911.

[12] Zhang CJ, Nicolosi V, Graphene and MXene-based transparent conductive electrodes and supercapacitors, Energy Stor. Mater. 2019, 16: 102-125.

[13] Chaudhari NK, Jin H, Kim B, et al. MXene: an emerging two-dimensional material for future energy conversion and storage applications, J. Mater. Chem. A 2017, 5: 24564-24579.

[14] Berdiyorov GR, Madjet ME, Mahmoud KA, et al. Ionic sieving through $\mathrm{Ti}_{3} \mathrm{C}_{2}(\mathrm{OH})_{2}$ MXene: firstprinciples calculations. Appl. Phys. Lett. 2016, 108(11): 113110.

[15] Seh ZW, Fredrickson KD, Anasori B, et al. Two-dimensional molybdenum carbide (MXene) as an efficient electrocatalyst for hydrogen evolution, ACS Energy Lett. 2016, 1(3): 589-594.

[16] Shahzad F, Alhabeb M, Hatter CB, et al. Electromagnetic interference shielding with 2D transition metal carbides (MXenes), Science 2016, 353: 1137-1140. 
[17] Halim J, Lukatskaya MR, Cook KM, et al. Transparent Conductive Two-Dimensional Titanium Carbide Epitaxial Thin Films, Chem. Mater. 2014, 26: 2374-2381.

[18] Naguib M, Kurtoglu M, Presser V, et al. Two-dimensional nanocrystals produced by exfoliation of $\mathrm{Ti}_{3} \mathrm{AlC}_{2}$, Adv. Mater. 2011, 23: 4248-4253.

[19] Liu YT, Zhu XD, Pan L, et al. Hybrid architectures based on 2D MXenes and low-dimensional inorganic nanostructures: methods, synergies, and energy-related applications, Smal/ 2018, 14(51): 1803632.

[20] Xu Y, Lin Z, Huang X, et al. Functionalized graphene hydrogel-based high-performance supercapacitors, Adv. Mater. 2013, 25: 5779-5784.

[21] Lei Z, Zhang J, Zhang LL, et al. Functionalization of chemically derived graphene for improving its electrocapacitive energy storage properties, Energy Environ. Sci. 2016, 9: 1891-1930.

[22] Jiang L, Sheng L, Long $C$, et al. Functional pillared graphene frameworks for ultrahigh volumetric performance supercapacitors, Adv. Energy Mater. 2015, 5: 1500771.

[23] Lian G, Tuan CC, Li L, et al. Ultrafast molecular stitching of graphene films at the ethanol/water interface for high volumetric capacitance, Nano Lett. 2017, 17: 1365-1370.

[24] Yu H, Xu P, Lee DW, et al. Porous-layered stack of functionalized AuNP-rGO (gold nanoparticlesreduced graphene oxide) nanosheets as a sensing material for the micro-gravimetric detection of chemical vapor, J. Mater. Chem. A 2013, 1: 4444-4450.

[25] Wu M, He Y, Wang L, et al. Synthesis and electrochemical properties of $V_{2} C$ MXene by etching in opened/closed environments. J. Adv. Ceram. 2020: 1-10.

[26] Zhao MQ, Ren CE, Ling Z, et al. Flexible MXene/carbon nanotube composite paper with high volumetric capacitance. Adv. Mater. 2015, 27(2): 339-345.

[27] Yan J, Ren CE, Maleski K, et al. Flexible MXene/graphene films for ultrafast supercapacitors with outstanding volumetric capacitance. Adv. Funct. Mater. 2017, 27(30): 1701264.

[28] Xu S, Wei G, Li J, et al. Flexible MXene-graphene electrodes with high volumetric capacitance for integrated co-cathode energy conversion/storage devices. J. Mater. Chem. A 2017, 5(33): 17442-17451.

[29] Boota M, Anasori B, Voigt C, et al. Pseudocapacitive electrodes produced by oxidant-free polymerization of pyrrole between the layers of 2D titanium carbide (MXene). Adv. Mater. 2016, 28(7): 1517-1522.

[30] Chen C, Boota M, Xie X, et al. Charge transfer induced polymerization of EDOT confined between 2D titanium carbide layers. J. Mater. Chem. A 2017, 5(11): 5260-5265. 
[31] VahidMohammadi A, Moncada J, Chen $\mathrm{H}$, et al. Thick and freestanding MXene/PANI pseudocapacitive electrodes with ultrahigh specific capacitance. J. Mater. Chem. A 2018, 6(44): 2212322133.

[32] Khamlich S, Khamliche T, Dhlamini MS, et al. Rapid microwave-assisted growth of silver nanoparticles on 3D graphene networks for supercapacitor application, J. Colloid Interface Sci. 2017, 493: 130-137.

[33] Dong $X$, Huang W, Chen $P$, et al. In situ synthesis of reduced graphene oxide and gold nanocomposites for nanoelectronics and biosensing, Nanoscale Res. Lett. 2011, 6(1): 60.

[34] Yan Y, Wang T, Li X, et al. Noble metal-based materials in high-performance supercapacitors, Inorg. Chem. Front. 2017, 4: 33-51.

[35] Alhabeb M, Maleski K, Anasori B, et al. Guidelines for synthesis and processing of two-dimensional titanium carbide $\left(\mathrm{Ti}_{3} \mathrm{C}_{2} \mathrm{~T}_{x} \mathrm{MXene}\right)$, Chem. Mat. 2017, 29: 7633-7644.

[36] Zhang L, Chen G, Hedhili MN, et al. Three-dimensional assemblies of graphene prepared by a novel chemical reduction-induced self-assembly method, Nanoscale 2012 4: 7038-7045.

[37] Tang Y, Zhu J, Yang C, et al. Enhanced capacitive performance based on diverse layered structure of two-dimensional $\mathrm{Ti}_{3} \mathrm{C}_{2}$ MXene with long etching time, J. Electrochem. Soc. 2016, 163: A1975.

[38] Rakhi RB, Ahmed B, Hedhili MN, et al. Effect of postetch annealing gas composition on the structural and electrochemical properties of $\mathrm{Ti}_{2} \mathrm{CT}_{\mathrm{x}} \mathrm{MXene}$ electrodes for supercapacitor applications, Chem. Mat. 2015, 27: 5314-5323.

[39] Peng $\mathrm{C}$, Yang $\mathrm{X}$, Li Y, et al. Hybrids of two-dimensional $\mathrm{Ti}_{3} \mathrm{C}_{2}$ and $\mathrm{TiO}_{2}$ exposing $\{001\}$ facets toward enhanced photocatalytic activity, ACS Appl. Mater. Interfaces 2016, 8: 6051-6060.

[40] Halim J, Cook KM, Naguib M, et al. X-ray photoelectron spectroscopy of select multi-layered transition metal carbides (MXenes), Appl. Surf. Sci. 2016, 362: 406-417.

[41] Cheng R, Hu T, Hu M, et al. MXenes induce epitaxial growth of size-controlled noble nanometals: A case study for surface enhanced Raman scattering (SERS), J. Mater. Sci. Technol. 2020, 40: 119-127.

[42] Zhou X, Huang X, Qi X, et al. In situ synthesis of metal nanoparticles on single-layer graphene oxide and reduced graphene oxide surfaces, J. Phys. Chem. C 2009, 113: 10842-10846.

[43] Li H, Hou Y, Wang F, et al. Flexible all-solid-state supercapacitors with high volumetric capacitances boosted by solution processable MXene and electrochemically exfoliated graphene, Adv. Energy Mater. 2017, 7: 1601847. 
[44] Singh SK, Dhavale VM, Boukherroub R, et al. N-doped porous reduced graphene oxide as an efficient electrode material for high performance flexible solid-state supercapacitor, Appl. Mater. Today 2017, 8: 141-149.

[45] Tang J, Mathis TS, Kurra N, et al. Tuning the electrochemical performance of titanium carbide MXene by controllable in situ anodic oxidation. Angew. Chem. Int. Ed. 2019, 58(49): 17849-17855.

[46] Atar N, Eren T, Yola ML, et al. Fe@ Ag nanoparticles decorated reduced graphene oxide as ultrahigh capacity anode material for lithium-ion battery. Ionics 2015, 21(12): 3185-3192.

[47] Ghidiu M, Kota S, Halim J, et al. Alkylammonium cation intercalation into $\mathrm{Ti}_{3} \mathrm{C}_{2}$ (MXene): Effects on properties and ion-exchange capacity estimation, Chem. Mat. 2017, 29: 1099-1106.

[48] Ghidiu M, Lukatskaya MR, Zhao MQ, et al. Conductive two-dimensional titanium carbide 'clay' with high volumetric capacitance, Nature 2014, 516: 78-81.

[49] Mashtalir O, Lukatskaya MR, Kolesnikov Al, et al. The effect of hydrazine intercalation on the structure and capacitance of 2D titanium carbide (MXene), Nanoscale 2016, 8: 9128-9133.

[50] Muhammad B, Babak A, Cooper V, et al. Pseudocapacitive electrodes produced by oxidant-free polymerization of pyrrole between the layers of 2D titanium carbide (MXene), Adv. Mater. 2016, 28:15171522.

[51] Wen Y, Rufford TE, Chen X, et al. Nitrogen-doped $\mathrm{Ti}_{3} \mathrm{C}_{2} \mathrm{~T}_{\mathrm{x}} \mathrm{MXene}$ electrodes for high-performance supercapacitors, Nano Energy 2017, 38: 368-376.

[52] Zhao MQ, Ren CE, Ling Z, et al. Flexible MXene/carbon nanotube composite paper with high volumetric capacitance, Adv. Mater. 2015, 27: 339-345.

[53] Ren Y, Zhu J, Wang L, et al. Synthesis of polyaniline nanoparticles deposited on two-dimensional titanium carbide for high-performance supercapacitors, Mater. Lett. 2018, 214: 84-87.

[54] Xu S, Wei G, Li J, et al. Binder-free $\mathrm{Ti}_{3} \mathrm{C}_{2} \mathrm{~T}_{x}$ MXene electrode film for supercapacitor produced by electrophoretic deposition method, Chem. Eng. J. 2017, 317: 1026-1036.

[55] Tang Y, Zhu J, Wu W, et al. Synthesis of nitrogen-doped two-dimensional $\mathrm{Ti}_{3} \mathrm{C}_{2}$ with enhanced electrochemical performance, J. Electrochem. Soc. 2017, 164: A923-A929.

[56] Yang C, Que W, Yin X, et al. Improved capacitance of nitrogen-doped delaminated two-dimensional titanium carbide by urea-assisted synthesis, Electrochim. Acta. 2017, 225: 416-424.

[57] Couly C, Alhabeb M, Van Aken KL, et al. Asymmetric flexible MXene-reduced graphene oxide microsupercapacitor, Adv. Electron. Mater. 2018, 4: 1700339. 
[58] Xia QX, Fu J, Yun JM, et al. High volumetric energy density annealed-MXene-nickel oxide/MXene asymmetric supercapacitor, RSC Adv. 2017, 7: 11000-11011.

[59] Lukatskaya MR, Mashtalir O, Ren CE, et al. Cation intercalation and high volumetric capacitance of two-dimensional titanium carbide, Science 2013, 341: 1502-1505.

[60] Fan Z, Wang Y, Xie Z, et al. A nanoporous MXene film enables flexible supercapacitors with high energy storage, Nanoscale 2018, 10: 9642-9652.

\section{Figures}

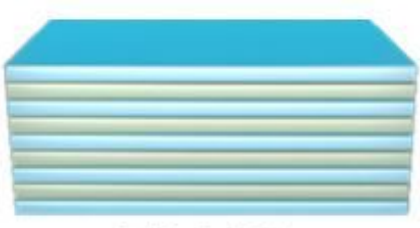

$\mathrm{Ti}_{3} \mathrm{AlC}_{2}$
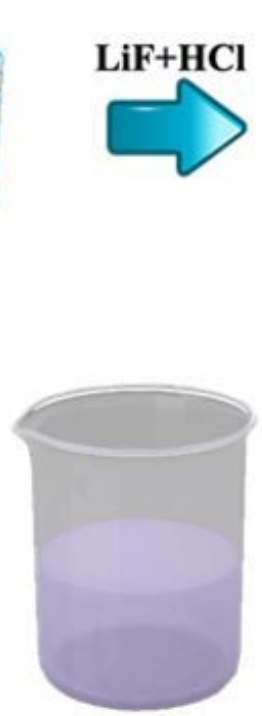

$\mathrm{HAuCl}_{4}$

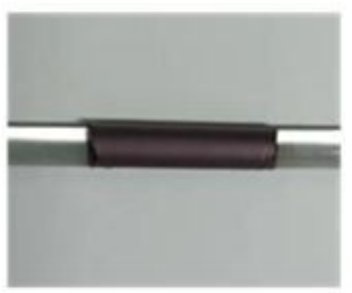

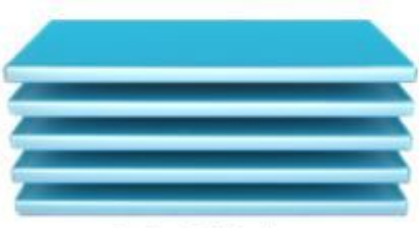

$\mathrm{Ti}_{3} \mathbf{C}_{2} \mathbf{T}_{\mathbf{X}}$
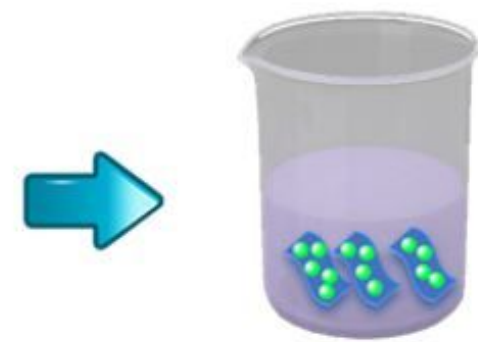

MXene/AuNPs
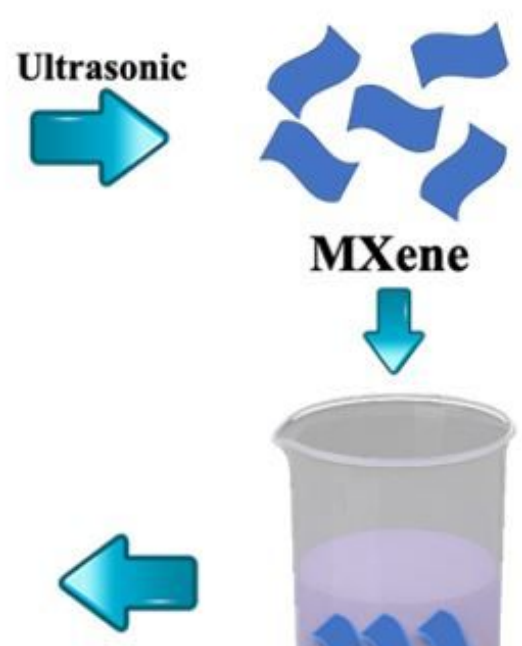

MXene
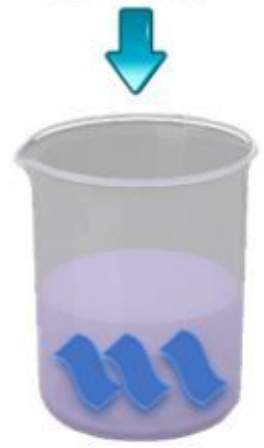

MXene solution
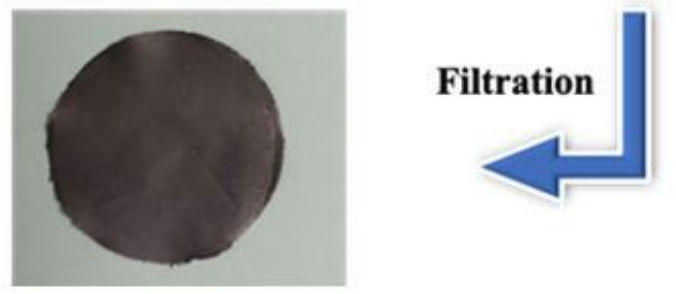

Figure 1

Schematic of the synthesis of MXene/AuNPs composite film. 


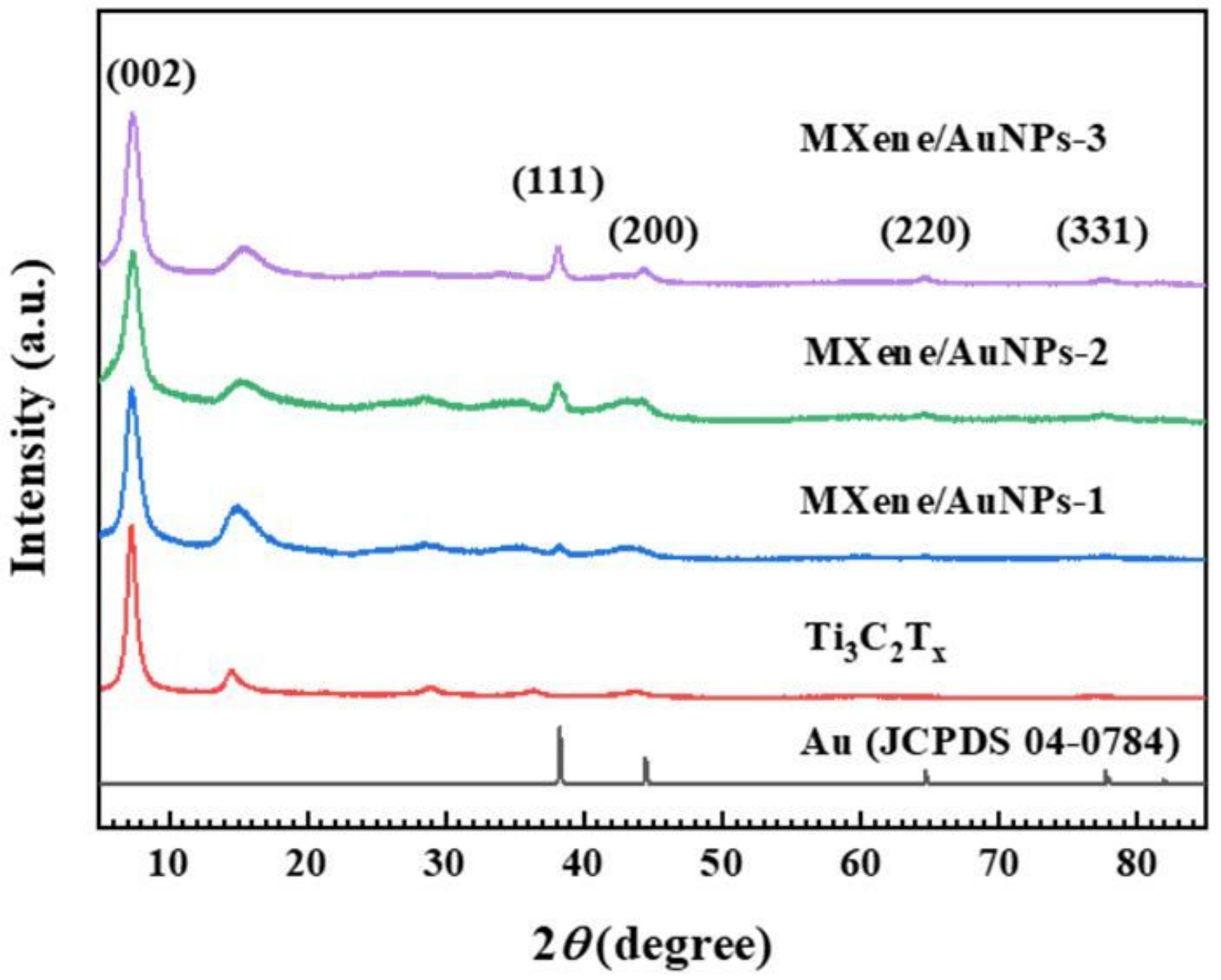

Figure 2

XRD patterns of MXene/AuNPs, Ti3C2Tx and AuNPs. 

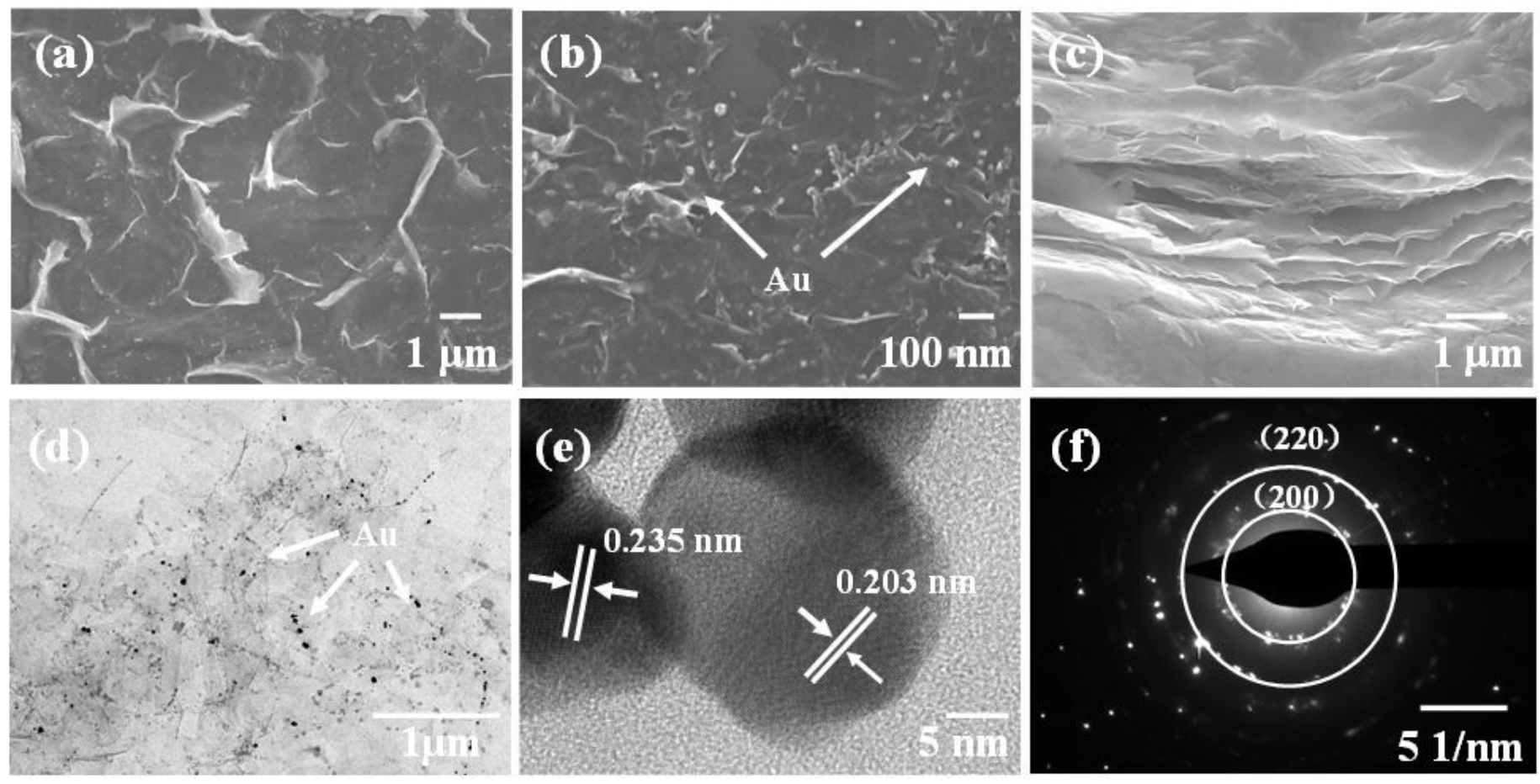

\section{Figure 3}

(a)-(b) Different magnifications SEM images of MXene/AuNPs composite film, (c) the cross-sectional SEM image of MXene/AuNPs composite film, (d) TEM image of MXene/AuNPs composite, (e) HRTEM image of MXene/AuNPs composite, (d) SAED pattern of MXene/AuNPs composite.
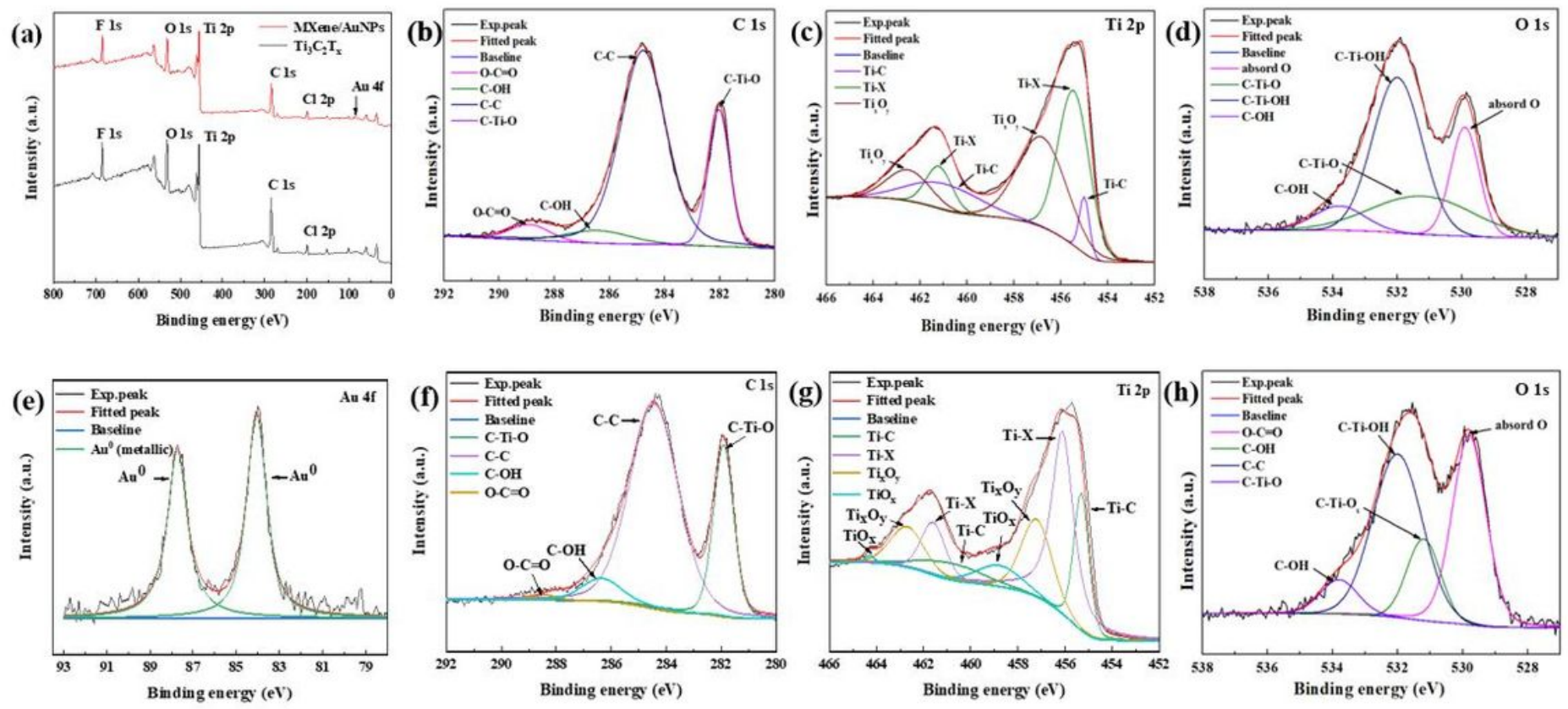

Figure 4 
(a) XPS full profiles of Ti3C2Tx and MXene/AuNPs samples. High resolution XPS spectrum of (b) C $1 \mathrm{~s}$ for Ti3C2Tx, (c) Ti 2p for Ti3C2Tx, (d) O 1s for Ti3C2Tx, (e)Au 4f for MXene/AuNPs, (f) C 1s for MXene/AuNPs, (g) Ti 2p for MXene/AuNPs and (h) 0 1s for MXene/AuNPs.
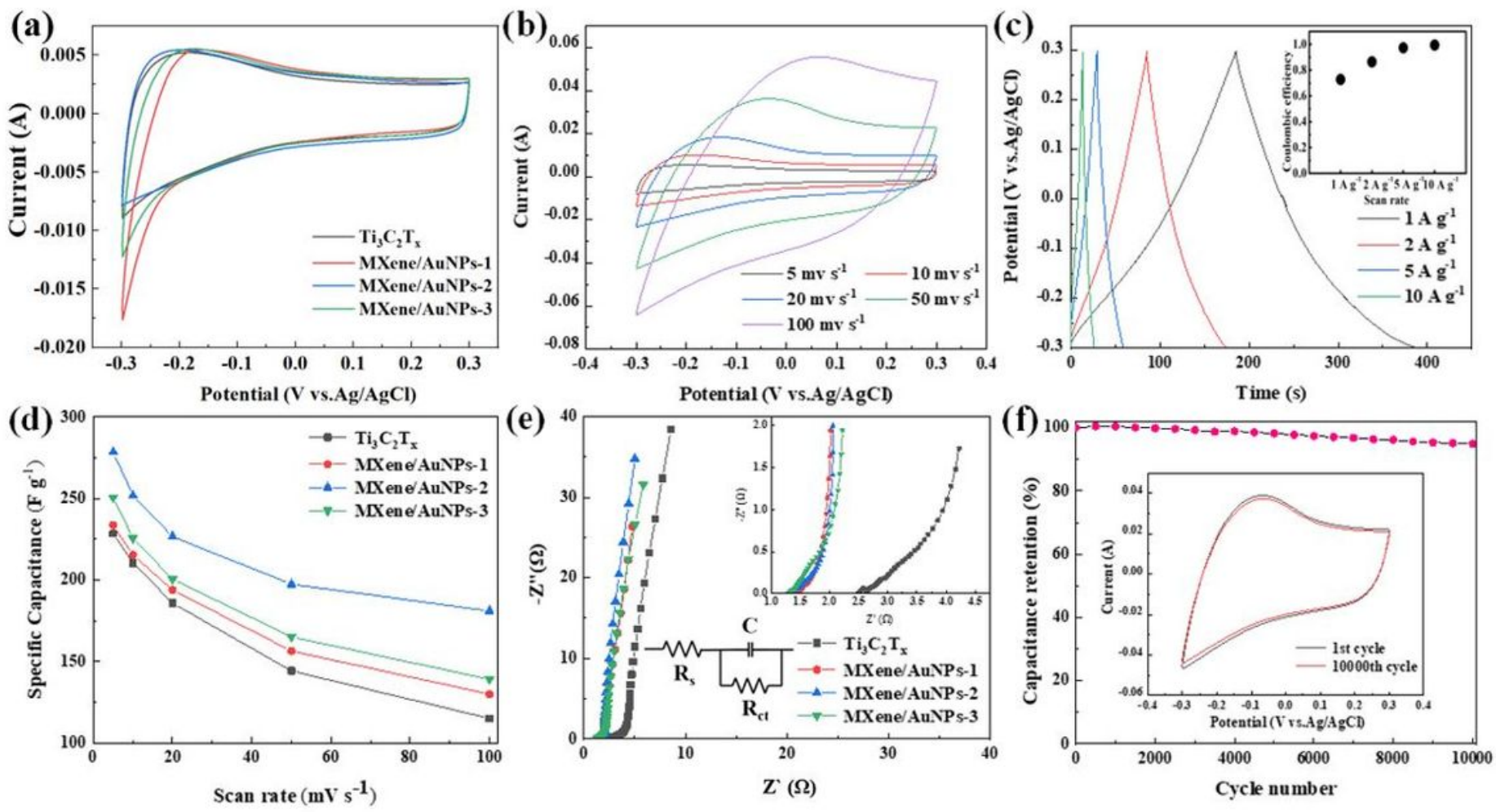

\section{Figure 5}

(a) CV curves of Ti3C2Tx and MXene/AuNPs electrodes, (b) CV curves of MXene/AuNPs-2 electrode with different scan rates, (c) GCDs of MXene/AuNPs-2 electrode with different current density, the inset is the coulombic efficiency (CE) caculated from different current density, (d) The specific capacitance of Ti3C2Tx and MXene/AuNPs electrode vs the scan rate, (e) Nyquist plots of Ti3C2Tx and MXene/AuNPs electrode, the insets are the magnified high-frequency region and the equivalent circuit diagram of the electrochemical system, (f) Cycling performance of MXene/AuNPs-2 after 10000 cycles. 
(a)

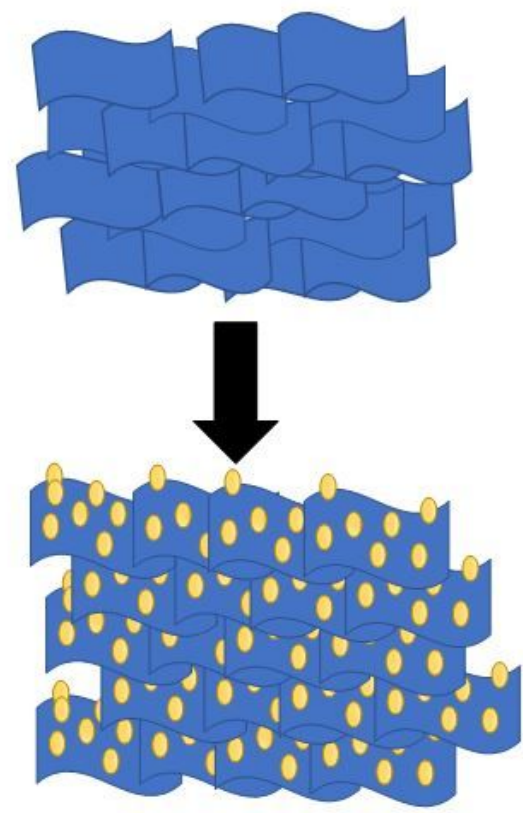

(b)

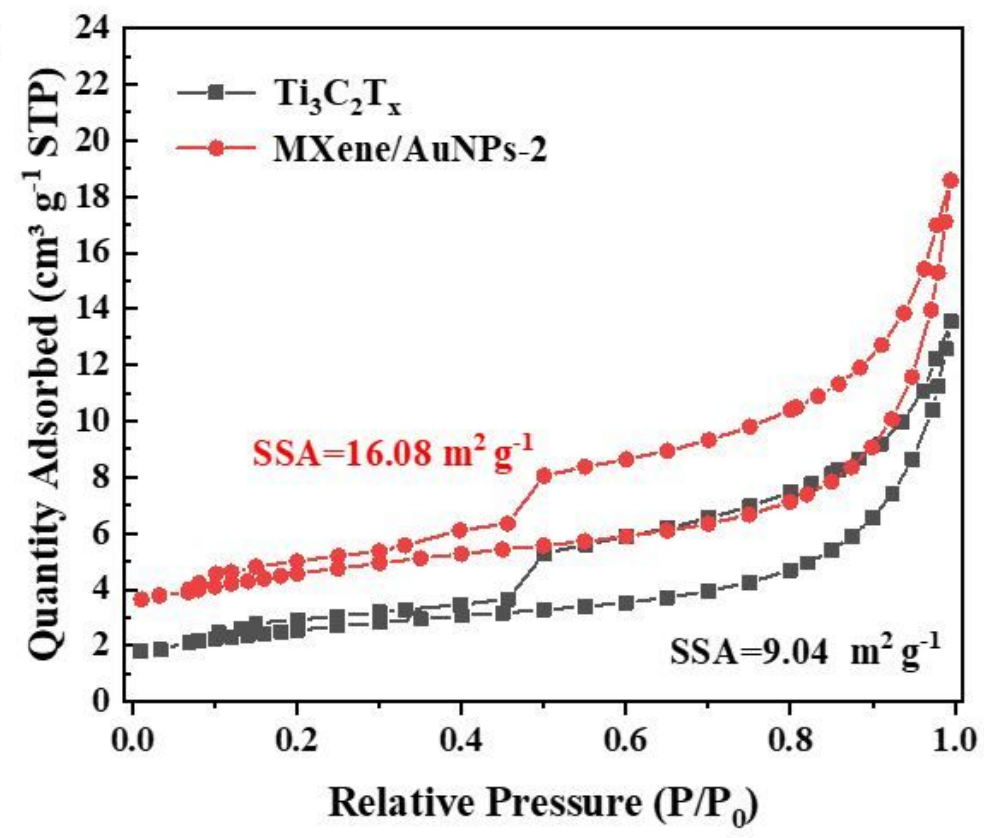

Figure 6

(a) Schematic illustration of Ti3C2Tx film and MXene/AuNPs film, (b) N2 adsorption-desorption curves of Ti3C2Tx film and MXene/AuNPs film.

(a)
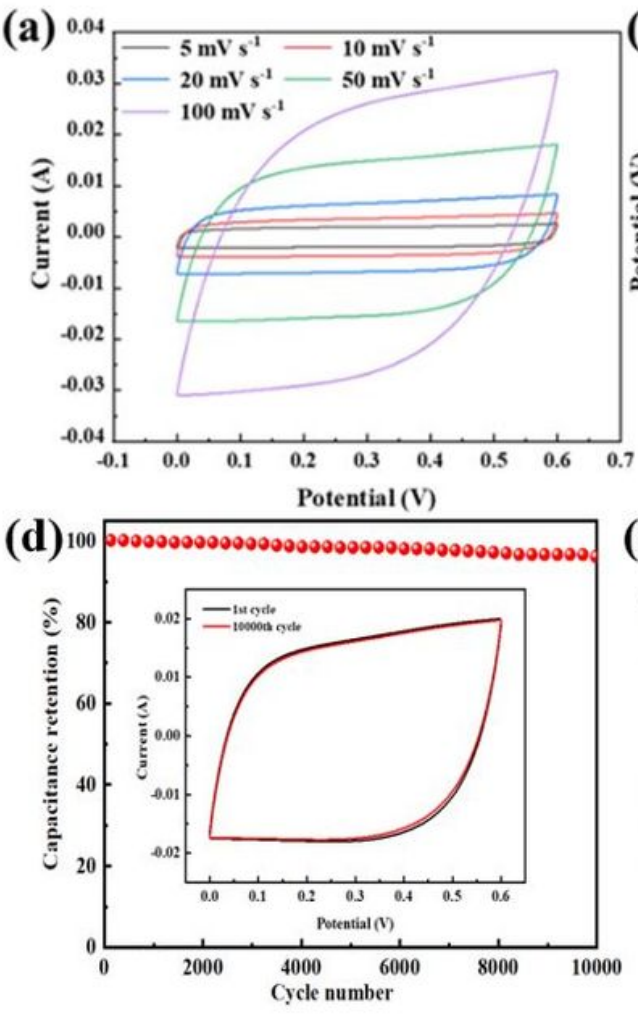

(b)

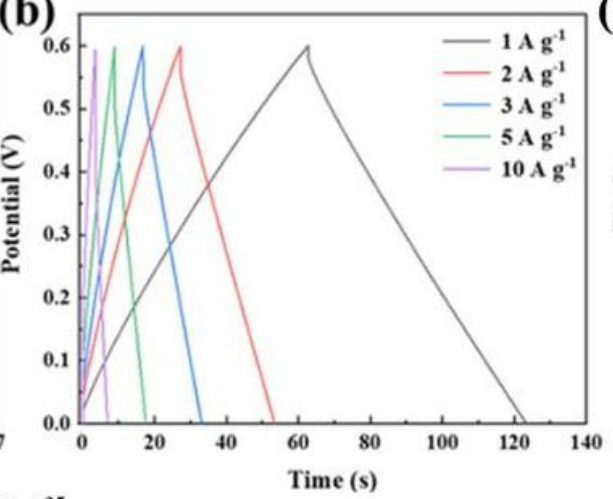

$(e)^{3}$

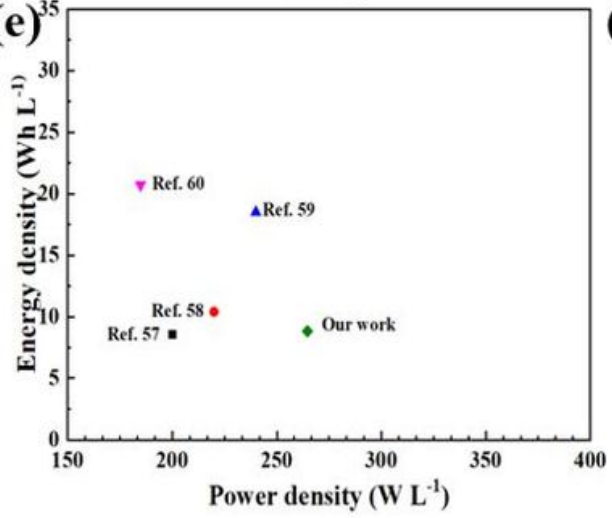

(c)

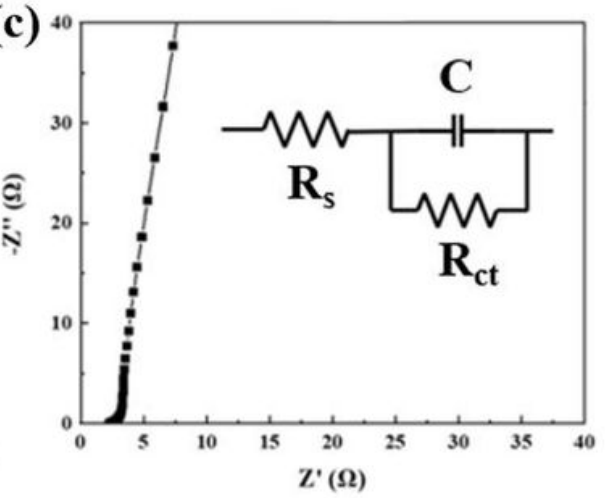

(f)

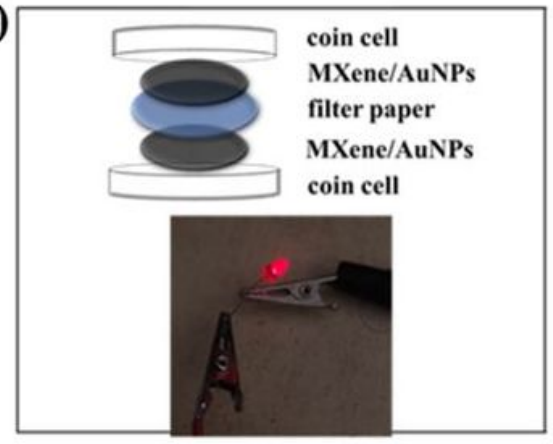

Figure 7 
(a) CV curves of MXene/AuNPs-2 symmetric supercapacitor, (b) GCDs of the supercapacitor, (c) Nyquist plots of the supercapacitor, inset is the equivalent circuit diagram of the electrochemical system, (d) Cycling performance of MXene/AuNPs-2 symmetric supercapacitor after 10000 cycles, (e) Volumetric energy and power density for the supercapacitors compared with other literatures, (f) schematic diagram of structure of symmetric supercapacitor.

\section{Supplementary Files}

This is a list of supplementary files associated with this preprint. Click to download.

- Supporting0204.docx 